\title{
Iniciação à pesquisa: um eixo de articulação no processo formativo de professores de ciências biológicas
}

\section{INTRODUCTION TO RESEARCH: A AXLE OF CONNECTIONS IN THE FORMATIVE PROCESS OF BIOLOGY TEACHERS}

\author{
Paulo Marcelo Marini Teixeira \\ $D C B-U E S B$ \\ E-mail :paulommt@hotmail.com \\ Departamento de Ciências Biológicas - UESB \\ $A v$. José M. Sobrinho, s/n - Jequié/BA \\ paulommt@zipmail.com.br
}

\section{Resumo:}

O presente artigo analisa o processo de iniciação à pesquisa em educação em ciências que vem sendo desenvolvido no curso de Licenciatura em Ciências Biológicas da UESB/Jequié/BA. A pesquisa foi desenvolvida entre 2002 e 2003, com o acompanhamento da trajetória de 12 licenciandos que participaram do processo desde a confecção do projeto de pesquisa até a entrega da monografia final. Para complementar a coleta de dados, foram realizadas entrevistas e análise documental, além do contato com os professores que atuaram como orientadores dos licenciandos. O objetivo da pesquisa foi detectar o impacto desse processo na formação dos licenciandos e, verificar se de alguma forma, a realização dos trabalhos de final de curso permite a articulação entre a área de conteúdos específicos e a área de formação pedagógica, contribuindo para construção de uma proposta curricular mais coesa, em que todos possam dar contribuição efetiva para formação do professor.

Palavras-chave: Ensino de Ciências; Formação de Professores; Pesquisa e Ensino.

\section{Abstract:}

This article analyzes the process of introduction into research in science education as part of the biology teaching major at the State University of South-Westerly of Bahia (UESB). The study, conducted during the years of 2002 and 2003, involved the experiences of 12 students who participated in the process from the elaboration of the research project until the conclusion of the final monograph. Data collection involved interviews and documentary analysis, besides contact with teachers who advised the students. The objective of the research was to detect the effects of this process in the education of undergraduate students, and to verify if the final assignments somehow supported the integration of the area of specific contents and the area of pedagogical education, adding to the construction of a curricular proposal, in which all can contribute effectively to teacher education.

Key-words: Science Education; Teacher Education; Research and Teaching. 


\section{INTRODUÇÃO}

Em 1999, o Departamento de Ciências Biológicas da Universidade Estadual do Sudoeste da Bahia (UESB) criou um novo curso de Licenciatura em Ciências Biológicas, substituindo o antigo curso de Ciências com Habilitação em Biologia. A proposta objetivou potencializar a formação de professores na área de ciências biológicas, na tentativa de aprimorar qualitativamente o processo formativo dos futuros professores, enfatizando a necessidade da universidade, por meio de seus cursos de graduação, resgatar a relevância dos cursos de licenciatura e capacitar profissionais que possam atuar como catalisadores de transformações no ensino público da região do semi-árido baiano, contribuindo para melhoria da qualidade de ensino na área de ciências.

O projeto do novo curso introduziu uma série de inovações, procurando romper com o tradicional modelo de formação $3+1^{1}$, que reduz a formação de professores, na maioria das vezes, aos conteúdos científicos (FURIÓ e GIL-PÉREZ, 1989). Um dos princípios elementares foi proporcionar aos alunos o contato com disciplinas de formação pedagógica desde o início do curso, articulando teoria e prática e as preocupações com o ensino de conteúdos na escola básica. Outro princípio foi tomar a prática como dimensão curricular, desde o início do curso, articulando-a com a teoria, e por fim, estimular uma concepção de formação de professores caracterizada pela pesquisa, vista como instrumento de modificação das posturas pedagógicas conservadoras e de busca constante por alternativas didáticas voltadas para formação de indivíduos críticos e reflexivos, capazes de atuarem autonomamente na sociedade contemporânea, conhecendo a realidade e enfrentando os problemas sociais.

Nesse sentido os licenciandos estão sendo encorajados a participar de projetos de pesquisa desde o início do curso, atuando como colaboradores, bolsistas e como voluntários em projetos de iniciação científica nas áreas de biologia geral, botânica, ecologia, zoologia, genética e educação em ciências. Ademais, nos três semestres finais do curso o aluno entra em contato com três disciplinas que têm a função de proporcionar as experiências de estágio e articular o projeto de pesquisa em educação em ciências, que dará suporte para confecção da monografia de final de curso (TCC).

A pesquisa aqui apresentada faz parte de um projeto mais amplo, objetivando detectar até que ponto, as iniciativas e modificações criadas nesta proposta de licenciatura vêm contribuindo para a formação de docentes suficientemente preparados para atuarem como professores pesquisadores; e analisar se o processo subjacente à confecção dos trabalhos de final de curso, pode viabilizar efetivamente um canal de articulação entre o trabalho realizado pelos professores que atuam na área de conteúdos específicos e os que atuam na área pedagógica e prática de ensino.

\footnotetext{
${ }^{1}$ Segundo Nagle (1987) esse é um dos modelos largamente utilizados nos cursos de licenciatura, com ênfase inicial nas chamadas disciplinas de conteúdo e depois, geralmente no último quarto do curso, passa-se a ministrar algumas aulas de disciplinas de natureza pedagógica.
} 


\section{PESQUISA COMO PRINCÍPIO NA FORMAÇÃO DE PROFESSORES}

É sabido por todos aqueles dedicados ao estudo das mazelas existentes na educação brasileira, que um dos grandes problemas que ainda demanda equacionamento é a questão da formação dos educadores. Em função disso, a formação de professores é temática que ocupa papel de destaque nas discussões político-educacionais (MACHADO, 1999, p. 95). Em que pesem inovações e idéias que permearam o cenário educacional deste país nos últimos 30 anos, é preciso admitir que pouca coisa mudou no que diz respeito ao processo formativo dos professores. "A formação de professores, na maioria dos cursos, ainda está mais próxima dos anos 1970 do que de hoje" (DELIZOICOV et al., 2002, p. 41). Prova disso é visualizada cotidianamente nas escolas de ensino básico, onde encontramos professores desenvolvendo prática pedagógica que reflete diretamente a formação obtida nos cursos de graduação. Diversos autores constataram que, apesar das repulsas verbais demonstradas pelos docentes em relação ao ensino tradicional, eles continuam fazendo em suas aulas, o mesmo que se fazia há 60 anos (YAGER e PENICK, 1983; GIL-PÉREZ e CARVALHO, 2000).

O ensino permanece sendo desenvolvido pela simples transmissão de conhecimentos, distanciado das propostas oriundas da pesquisa didática e ignorando os resultados obtidos a partir dela. Além disso, a tradição dos esquemas de formação docente fomenta a separação entre a investigação e a prática pedagógica e ainda, entre planejadores e executores. A função docente é esvaziada ao sofrer uma desqualificação, posto que o professor é transformado em mero executor daquilo que os "especialistas" pensam e não exerce a elaboração da ação, isto é, a investigação e a decisão sobre questões de natureza pedagógica ${ }^{2}$.

No conjunto das propostas que apareceram nos últimos tempos, na tentativa de incrementar a formação dos futuros docentes, encontra-se a idéia de inserir no processo formativo dos professores a iniciação à pesquisa. A adoção de episódios de pesquisa, ou de iniciação à pesquisa vem sendo recomendada com ênfase por diversos autores (MOREIRA, 1991; PORLÁN, 1987; DEMO, 1997; LÜDKE, 2001; SCHÖN, 1992). Embora não seja proposta nova ${ }^{3}$, certamente ainda há dificuldades para operacionalizar a dimensão da pesquisa no ensino de graduação e nos programas de formação continuada. O maior obstáculo está em "superar a visão unilateral de considerar como pesquisa apenas seus estágios sofisticados, representados pelos produtos solenes do mestre ou do doutor", e no argumento equivocado de que pesquisa é coisa específica de pós-graduação (DEMO, 2002, p. 10). Outro aspecto limitante para o processo de produção de pesquisa é a "primazia do ensino sobre a pesquisa no âmbito das universidades, deixando aos docentes pesquisadores pouca disponibilidade de tempo para a pesquisa e orientação" (ALVESMAZZOTTI, 2001, p. 40).

Sem deixar de reconhecer tais dificuldades, nos últimos 30 anos se consolidou na discussão acadêmica "uma perspectiva de valorização da pesquisa e de estímulo ao seu desenvolvimento entre as atividades" dos professores da educação básica (LÜDKE, 2001, p. 96), sobretudo no sentido proposto por Schön (1992), que difundiu a idéia do professor que

\footnotetext{
${ }^{2}$ MACHADO, op. cit., p. 96.

3 A Conferência Internacional da Instrução Pública de 1958, na recomendação n. 46, art. 15, referia-se a necessidade de impulsionar a pesquisa realizada pelos professores [ $c f$. Serramona (1980) apud Gil-Pérez (2000)].
} 
reflete sobre sua prática, antes que ela ocorra, durante o seu desenvolvimento e após sua conclusão, num processo de retro-alimentação da prática docente.

Documentos oficiais que emitem diretrizes para os cursos de formação de professores destacam a importância da pesquisa nos cursos de graduação. A resolução $\mathrm{CNE} / \mathrm{CP} 1^{4}$, em seu Art. $2^{\circ}$, indica que a organização curricular desses cursos deve considerar a preparação e o aprimoramento em práticas investigativas. Entre os princípios norteadores para a preparação de profissionais que atuarão nas diferentes modalidades da educação básica está a questão da pesquisa, com foco no processo de ensino e de aprendizagem. Finalmente, em seu artigo $6^{\circ}$, a resolução ressalta que os projetos pedagógicos devem contemplar "competências referentes ao conhecimento de processos de investigação que possibilitem o aperfeiçoamento da prática pedagógica".

$\mathrm{Na}$ esteira dos pesquisadores que defendem a introdução da pesquisa nos cursos de formação (inicial e permanente) de professores, podem ser encontrados recentemente diversos trabalhos. Gil-Pérez e Carvalho (2000), consideram a iniciação do licenciando à pesquisa como requisito básico para sua formação. Os autores estabeleceram necessidades formativas para o professor de ciências, destacando a utilização da pesquisa e das inovações didáticas. Outro requisito seria adquirir formação necessária para associar ensino e pesquisa. Eles argumentam também que os professores, amiúde, têm pouca familiaridade com as contribuições da pesquisa e inovações didáticas, o que explica porquê existe distância considerável entre o que os pesquisadores apresentam como propostas e o que os professores efetivamente incorporam à sua prática pedagógica. Ademais, dificilmente o docente orientará a aprendizagem de seus alunos como uma construção de conhecimentos científicos, isto é, como pesquisa, se ele próprio não possuir vivência em práticas investigativas (GIL-PÉREZ, 2000, p. 62).

A separação entre o trabalho de pesquisadores e professores também foi fato constatado por Delizoicov et al. (2002), evidenciando a existência de uma disseminação razoável dos resultados das pesquisas entre os pesquisadores que pertencem à área de ensino de ciências: "No entanto, a apropriação, a reconstrução e o debate sistemático dos resultados de pesquisa na sala de aula e na prática docente dos professores dos três níveis são sofríveis" (DELIZOICOV et al., 2002, p. 40). Para os autores, os novos conhecimentos oriundos da área de pesquisa em ensino de ciências precisam permear as ações docentes e se tornar objeto de estudo e discussão no currículo das licenciaturas.

Gradativamente, algumas experiências começaram a ser desenvolvidas no sentido de colocar a dimensão da pesquisa no processo formativo dos professores. Por exemplo, Bastos e Caldeira (2000), fizeram esforços para compatibilizar os estágios de observação e o estágio de regência com pequenos projetos de pesquisa. O trabalho de Galiazzi e Moraes (2001) também investigou experiências interessantes de utilização da pesquisa como princípio didático em cursos de licenciatura. Os autores enfatizam que a inserção da pesquisa pode colaborar na construção da competência do professor e na transformação dos cursos de formação, integrando disciplinas de conteúdo pedagógico e conteúdos específicos; viabilizando a construção de uma proposta curricular menos fragmentada e que integra professores de diversas áreas.

\footnotetext{
${ }^{4}$ Resolução CNE/CP1, que institui as Diretrizes Curriculares Nacionais para a Formação de Professores da Educação Básica, em nível superior, curso de licenciatura, de graduação plena (D.O.U.: 04/03/2002. Seção 1, p.8).
} 
$\mathrm{Na}$ área da formação continuada as experiências ainda são raras, demandando atenção por parte dos estruturadores de programas de capacitação e atualização de professores. Via de regra, esses cursos estão centrados no resgate de conteúdos específicos e de prescrições pedagógicas de caráter genérico que não têm reflexo na prática pedagógica dos professores.

Experiência interessante e inovadora foi relatada por Vianna e Carvalho (2001). As pesquisadoras entrevistaram professores em atividade, que estavam participando de um curso de formação, que em certo momento procurou "mostrar a ciência que é feita nos laboratórios pelos cientistas": conhecimento sobre as práticas dos pesquisadores, o que fazem, dizem, como se comportam, como interagem e como vão construindo conhecimentos e publicam (divulgam) o produto de seu trabalho.

As investigações mencionadas e os resultados derivados a partir desses trabalhos indicam que é mister incentivar a ocorrência de episódios de pesquisa na formação dos educadores. No Brasil, um dos principais defensores dessa tese é o Professor Pedro Demo. Para o autor é necessário:

(...) consolidar ambiente acadêmico comprometido, nos alunos e nos professores, com pesquisa, elaboração própria, produtividade, mérito; (...) exigir, ao final do curso, a feitura de trabalho científico denso, cuja função principal é demonstrar que o aluno é capaz de construir projeto pedagógico próprio (DEMO, 1997, p. 94).

Nessa perspectiva, merece especial atenção a introdução de trabalhos de final de curso confeccionados pelos licenciandos sob orientação dos professores. Pedro Demo considera o TCC parte essencial do desempenho qualitativo do aluno. O TCC pode ser definido como momento privilegiado para que o estudante de graduação demonstre capacidade de projeto próprio, teórico e prático. A vantagem desse tipo de trabalho é que ele representa um passo à frente, motivando os estudantes para interpretações próprias, estimulando postura crítico-reflexiva e proporcionando aos futuros docentes, instrumentos para o desenvolvimento do pensamento autônomo (NÓVOA, 1992).

Quanto ao problema da avaliação dos trabalhos de final de curso, a idéia é que "esse tipo de trabalho deveria ser avaliado por dois ou três professores, incluindo o orientador, para dar maior destaque em termos de mérito formal e político" (DEMO, 2002, p. 113).

Com efeito, a introdução dos trabalhos de final de curso, como componente curricular dos cursos de formação docente, tem papel decisivo na construção da competência do futuro professor e é um dos expedientes que vem sendo adotado cada vez mais nos cursos de licenciatura, com resultados bastante animadores.

\section{A PESQUISA REALIZADA}

Acompanhamos uma turma de 12 licenciandos do curso de Licenciatura em Ciências Biológicas da UESB, campus de Jequié/BA, durante três semestres letivos ${ }^{5}$. Além das observações, foram realizadas algumas entrevistas semi-estruturadas com os alunos e conversas informais com os professores que se envolveram de alguma forma nos trabalhos de pesquisa desenvolvidos nesse período. Os professores em questão atuaram como

\footnotetext{
${ }^{5}$ Os trabalhos foram finalizados em Abril de 2003.
} 
orientadores ou pareceristas dos trabalhos apresentados pelos licenciandos. As entrevistas foram gravadas em áudio. Uma cópia de cada monografia foi também requerida para breve levantamento de informações e análise dos trabalhos investigativos realizados. Foram também analisados alguns documentos como pareceres e resoluções do Ministério da Educação (MEC) sobre a formação de professores; o projeto de reconhecimento do curso de Licenciatura em Ciências Biológicas da UESB/Jequié; e, a grade curricular que contém a estrutura disciplinar deste curso. A análise dos dados coletados foi orientada pelos princípios da pesquisa qualitativa em educação. Portanto, a pesquisa envolveu a obtenção de dados descritivos, obtidos a partir do contato do pesquisador com a realidade estudada ${ }^{6}$, enfatizando mais o processo do que o produto e se preocupando com a perspectiva dos participantes (LÜDKE e ANDRÉ, 1986; BOGDAN e BIKLEN, 1994).

\section{RESULTADOS E DISCUSSÃO}

A documentação analisada comprova que a intenção dos estruturadores do curso está vinculada à formação de professores identificados com perfil diferenciado, qual seja, profissional que alie convenientemente ensino à pesquisa. $O$ projeto de reconhecimento do curso, em sua proposta para a prática de ensino e estágio supervisionado vincula a preparação para a docência a um processo de iniciação à pesquisa em educação, com ênfase em temáticas associadas ao ensino de ciências e biologia. $O$ documento é claro ao enfatizar que esse é um dos objetivos perseguidos durante o processo formativo:

Proporcionar iniciação dos aprendizes nas experiências de iniciação à pesquisa, como forma de viabilizar a construção de um perfil de profissionais que tenham na pesquisa elemento central de sua atuação (Projeto de Reconhecimento ${ }^{7}$ ).

Ao analisar a grade curricular do referido curso, detectamos que a parte do currículo dedicada à prática de ensino e estágio supervisionado estabelece três modalidades de estágio: 1) prática de ensino (observação, co-participação, regência); 2) estágio na forma de extensão (mini-cursos preparados e ministrados pelos licenciandos sob orientação dos professores de prática de ensino); e 3) pesquisa orientada.

O documento explicita que os licenciandos deverão: "Elaborar projeto de pesquisa qualitativa em educação, que tenha como problema alguma temática ligada ao ensino de ciências e/ou biologia" (Projeto de Reconhecimento).

A organização das disciplinas responsáveis por este processo pode ser visualizada no quadro abaixo:

\footnotetext{
${ }^{6} \mathrm{O}$ pesquisador é professor deste curso atuando nas disciplinas ligadas à prática de ensino e estágio supervisionado.

${ }^{7}$ O curso em questão está em fase de reconhecimento. Após a visita dos membros do Conselho Estadual da Educação, serão propostas algumas reformulações visando aprimorar a proposta e também dar início às discussões para a reformulação do projeto pedagógico.
} 
Quadro 1 - Disciplinas do curso de licenciatura estruturadas para articular prática de ensino, estágio e iniciação à pesquisa.

\begin{tabular}{|c|c|c|c|}
\hline Disciplinas & $\begin{array}{l}\text { Carga } \\
\text { Horária }\end{array}$ & $\begin{array}{c}\text { Objetivos previstos para a iniciação à } \\
\text { pesquisa }\end{array}$ & SEMESTRE \\
\hline $\begin{array}{l}\text { Metodologia da Pesquisa } \\
\text { Científica }\end{array}$ & 60 & $\begin{array}{l}\text { Estabelecer noções gerais sobre metodologia da } \\
\text { pesquisa científica }\end{array}$ & III \\
\hline $\begin{array}{c}\text { Seminários de } \\
\text { Pesquisa no ensino de } \\
\text { ciências e biologia }\end{array}$ & 90 & $\begin{array}{l}\text {-Apresentar um panorama das pesquisas } \\
\text { realizadas na área de ensino de ciências; } \\
\text {-Apresentar os fundamentos de metodologia de } \\
\text { pesquisa em educação em ciências; } \\
\text {-Confecção do projeto de pesquisa. }\end{array}$ & VI \\
\hline $\begin{array}{l}\text { Metodologia e Prática de } \\
\text { Ciências Naturais }\end{array}$ & 120 & $\begin{array}{c}\text { - Execução do projeto de pesquisa: } \\
\text { - } \quad \text { Coleta de dados; } \\
\text { - } \quad \text { Análise dos dados }\end{array}$ & VII \\
\hline $\begin{array}{c}\text { Metodologia e Prática de } \\
\text { Biologia }\end{array}$ & 150 & - Redação da Monografia. & VIII \\
\hline TOTAL & 420 & & \\
\hline
\end{tabular}

A primeira disciplina desta seqüência tem caráter mais amplo, destinando-se a construir as noções gerais sobre metodologia científica. Posteriormente, já no sexto semestre os alunos cursam uma disciplina que é peça-chave no processo de iniciação à pesquisa (Seminários de Pesquisa). Nesta etapa, os alunos tomam contato com um panorama das pesquisas realizadas nas últimas décadas na área de educação e ensino de ciências, com destaque para os trabalhos apresentados nas três primeiras edições do ENPEC $^{8}$ e nas revistas destinadas à divulgação de trabalhos na área de ensino de ciências no Brasil ${ }^{9}$. Os artigos que divulgam os resultados das pesquisas produzidas nessa área são objeto de leitura, discussão e apresentação de seminários. Concomitantemente, os alunos iniciam estudos para confecção do projeto de pesquisa e finalizam a disciplina com o projeto em condições de subsidiar o desenvolvimento da pesquisa na disciplina seguinte da seqüência (Metodologia e Prática de Ensino de Ciências Naturais).

A partir daí, os licenciandos têm dois semestres para finalizar a monografia, que deverá ser entregue na última unidade da disciplina Metodologia e Prática de Ensino de Biologia.

A orientação dos trabalhos de pesquisa fica por conta dos professores do curso de licenciatura. Na maioria dos casos, o que se verificou foi a estratégia de co-orientação, isto é, cada estudante dispondo de um orientador ligado à área de educação e prática de ensino, e um outro ligado a área específica (ecologia, botânica, genética, zoologia, biologia geral etc.).

A primeira turma a passar por esse processo encerrou as atividades em Abril/2003, com a entrega das respectivas monografias. Foram 12 alunos que desenvolveram diferentes trabalhos investigativos na área de ensino de ciências e biologia, conforme podemos mostrar sinteticamente no quadro abaixo:

\footnotetext{
${ }^{8}$ ENPEC: Encontro Nacional de Pesquisa em Educação em Ciências.

${ }^{9}$ Revistas utilizadas: Revista Brasileira de Pesquisa em Educação em Ciências (RBPEC); Ciência \& Educação; Investigações em Ensino de Ciências, Revista Ensaio (UFMG); Ciência \& Ensino (UNICAMP: gepCE).
} 
Quadro 2 - Projetos de pesquisa desenvolvidos pelos licenciandos.

\begin{tabular}{|c|c|c|c|}
\hline COD. & Temática de Pesquisa & Centro de Interesse & Área dos Orientadores ${ }^{10}$ \\
\hline 1. ELI & Educação Ambiental: Concepções dos alunos & Meio Ambiente & (1) Educação \\
\hline 2. EDI & Ensino de Zoologia: Metodologias alternativas & Cnidários & (2) Educação e Zoologia \\
\hline 3. LIS & Ensino de Ciências: Metodologia de ensino & $\begin{array}{l}\text { Diagnóstico da prática } \\
\text { docente }\end{array}$ & (1) Educação \\
\hline 4. RUB & Ensino de Botânica: Formação de professores & $\begin{array}{l}\text { Diagnóstico sobre ensino } \\
\text { de Biologia Vegetal }\end{array}$ & (2) Educação e Botânica \\
\hline 5. SIN & Ensino de Genética: Concepções dos alunos & Determinação do Sexo & (2) Educação e Genética \\
\hline 6. REN & Ensino de Genética: Concepções dos alunos & Divisão Celular & (2) Educação e Genética \\
\hline 7. ION & Ensino de Ciências: Concepções dos alunos & Respiração & (2) Educação e Fisiologia \\
\hline 8. MIL & Educação Ambiental & Sustentabilidade & (1) Educação \\
\hline 9. MON & Ensino de Zoologia: Análise de livro didático & Peixes & (2) Educação e Ecologia \\
\hline $\begin{array}{l}10 . \\
\text { TER }\end{array}$ & Ensino de Ciências/Biologia: & Combate às Drogas & (1) Educação \\
\hline 11. LIL & Ensino de Botânica: concepções dos alunos & Fotossíntese & (2) Educação e Botânica \\
\hline 12. ALE & Ensino de Botânica: ensino e aprendizagem & \begin{tabular}{|l} 
Nomenclatura em \\
Botânica e aprendizagem
\end{tabular} & (2) Educação e Botânica \\
\hline
\end{tabular}

Os trabalhos de pesquisa realizados pelos 12 alunos envolveram um total de 10 diferentes professores nos processos de orientação e co-orientação. Deste total, $80 \%$ são docentes responsáveis por disciplinas específicas e apenas $20 \%$ são professores da área pedagógica. Como se nota, o regime de co-orientação esteve presente em aproximadamente $66 \%$ dos projetos realizados, sempre num trabalho de articulação entre as áreas de conteúdos específicos e de conteúdos didáticos, concretizando caminho efetivo de integração, rompendo com a tradicional dicotomia entre essas áreas.

Outro momento que permitiu a articulação dos professores e alunos do curso foi verificado na composição dos grupos de pareceristas que avaliaram os respectivos trabalhos. Cada trabalho foi analisado por três professores, processo que acabou envolvendo um total de 20 docentes do Departamento de Ciências Biológicas, sendo que 18 desses professores ministram disciplinas de conteúdos específicos, configurando mais uma vez, ponto de articulação entre professores de áreas distintas em torno de projetos de investigação, que estavam associados às questões de ensino e aprendizagem de conteúdos em ciências e biologia.

Esse momento foi importante, porquê a maioria dos professores chamados a participar do processo, não tiveram experiências com pesquisa em educação, pois são docentes que fizeram seus cursos de Graduação e Pós-Graduação (mestrado e doutorado) em áreas específicas ligadas à biologia. Em muitos casos foi necessário que alunos e professores da área de educação e de conteúdos específicos, se reunissem para discutir pressupostos epistemológicos e metodológicos da pesquisa em questão, ocasionando situações interessantes, com a formulação de contribuições que, certamente, terão repercussão tanto na formação dos alunos, quanto na própria prática pedagógica dos docentes que atuam na licenciatura. Exemplo disso é que alguns textos e artigos específicos da área de pesquisa em ensino de ciências começam a ser utilizados pelos professores de

\footnotetext{
${ }^{10} \mathrm{O}$ número entre parênteses indica a quantidade de orientadores que apoiaram a execução do projeto.
} 
disciplinas específicas, o que remete para a idéia de uma preocupação com o ensino que antes não existia por parte dos professores das disciplinas de conteúdo específico.

Como apontou o trabalho realizado por Galiazzi e Moraes (2001), essa experiência coletiva permitiu a concretização da "construção de uma proposta curricular menos fragmentada do que as que freqüentemente aparecem" nos curso de graduação.

Esse processo enriqueceu consideravelmente a formação dos licenciandos, permitindo que eles tomassem contato com uma experiência inédita de associação entre pesquisa e ensino.

As entrevistas realizadas junto aos alunos revelaram que, embora alguns deles tivessem tido a oportunidade de participar de projetos de iniciação científica, essa foi a primeira experiência sistemática de pesquisa, envolvendo elaboração de projeto, orientações, coleta de dados, análise e redação da monografia, convidando os estudantes a enfrentar o desafio de desenvolver uma produção própria. Entre os trabalhos desenvolvidos, $50 \%$ foram submetidos para apresentação em diversos eventos de divulgação científica.

As entrevistas também acabaram revelando aspectos peculiares da trajetória desenvolvida por eles durante o trabalho de pesquisa. Eles destacaram como aspectos positivos do processo:

- A indução para a criação de hábitos sistemáticos de leitura: "o trabalho forçou a leitura, que é um hábito que eu ainda não tinha" (LIS);

- O despertar do interesse pela pesquisa;

- Levou a aprendizagem sobre como elaborar um projeto de pesquisa e executá-lo;

- A realização do trabalho parece ter contribuído para a formação de profissionais que possuem uma postura reflexiva diante da realidade escolar. Os alunos manifestaram capacidade para analisar a escola e o processo educativo com "olho clínico" e sistemático: "Porque se analisa a realidade da escola com o suporte de teorias específicas" (SIN);

- Auxiliou o desenvolvimento da autonomia para escrever (REN) e permitiu o contato na prática com as normas básicas para redação de trabalhos científicos;

- Incrementou as relações entre pesquisa e ensino e suas repercussões sobre a prática pedagógica: "A partir dessa monografia eu posso trabalhar qualquer outro tema por conta própria, e me sair bem com isso e obter bons resultados em sala de aula" (EDI);

- Motivou os estudantes para a continuidade dos estudos em nível de pósgraduação (especialização, mestrado e doutorado).

Parece claro que, essa experiência inicial com a pesquisa em educação foi crucial para cativar os alunos (licenciandos) para a pesquisa e para a postura reflexiva diante das questões que envolvem os problemas educacionais. Houve depoimentos de alunos que declararam que após este processo, passaram a ver a pesquisa como algo desejável inclusive para os professores do ensino fundamental e médio: "Como professor do ensino médio, vejo que a pesquisa pode ser feita no ensino básico. O professor tem como atuar (fazer) pesquisa para (...) lidar melhor com o processo de ensino e aprendizagem na sala de aula" (RUB). 
Alguns alunos também argumentaram que os professores do ensino básico deveriam ser incentivados a desenvolver pesquisa cotidianamente. Segundo eles, parte da carga horária semanal poderia ser dedicada à pesquisa aplicada às questões educacionais, instituindo o que Demo (2002), designa como proposta do educar pela pesquisa, fazendo dela atitude cotidiana nos professores e estudantes e desfazendo o mito e a expectativa arcaica de que pesquisa é atividade especial realizada por pessoas especiais.

Os alunos também mencionaram algumas dificuldades que estiveram presentes durante o processo. Os obstáculos mais freqüentemente mencionados foram os seguintes:

- Acervo bibliográfico deficiente na biblioteca do campus;

- Dificuldade na produção textual (redação da monografia);

- Dificuldades na delimitação do tema de pesquisa (em função da falta de experiência na realização de projetos de pesquisa);

- Tempo reduzido para análise dos dados e redação da monografia;

Como se nota, excluindo o primeiro aspecto mencionado, que se refere a um problema estrutural da universidade, que realmente possui acervo incipiente em suas biblioteca, principalmente no que se refere aos periódicos da área - os estudantes mencionaram problemas tipicamente vivenciados por aqueles que estão iniciando suas experiências na área de pesquisa acadêmica.

A dificuldade de elaboração própria de textos era esperada, visto que os cursos de graduação de modo geral, ainda lidam de forma superficial com a leitura e escrita de textos. São raros os professores que se preocupam sistematicamente em desenvolver essas habilidades nos graduandos, e nesse sentido, é preciso discutir estratégias efetivas para incentivar hábitos de leitura e escrita nos cursos de graduação. Portanto, é um dado que será levado em consideração nas discussões futuras sobre o curso. Como assevera A. J. Severino:

(...) no ensino superior, ler e escrever são processos fundamentais e imprescindíveis. Ler para se dar conta dos sentidos acumulados da cultura humana, bem como para extrair ferramentas específicas para a produção de novos significados. Escrever para consolidar a apreensão dos significados já disponíveis, interagindo com eles, bem como para disponibilizar os novos significados aos demais sujeitos, viabilizando o diálogo comunicativo, e para registrá-los no acervo cultural a ser legado à humanidade (SEVERINO, 2001, p.77).

Nesse sentido, a lida com textos é crucial, assim como, é fundamental que os alunos escrevam, refaçam estudos com linguagem própria, interpretem com autonomia e postura crítica.

A dificuldade na delimitação do tema de pesquisa (objeto de estudo) parece ser processo natural, tendo em vista que essa foi a primeira experiência de pesquisa vivenciada pela maioria dos licenciandos. Os seminários realizados durante a disciplina "SPEB"11 foram proveitosos porquê os alunos tiveram a oportunidade para conhecer diversas linhas e possibilidades de pesquisa existentes na área relativa ao ensino de ciências (livros didáticos; concepções espontâneas; mudança conceitual; educação ambiental; história da ciência etc.). Mesmo assim, alguns alunos apresentaram dificuldades para definir seus

\footnotetext{
${ }^{11}$ Seminários de Pesquisa no Ensino de Biologia.
} 
temas de pesquisa, o que parece um problema inevitável e natural, que entretanto pode ser dirimido com a ajuda dos orientadores.

Com relação ao tempo para análise dos dados e redação final da monografia, a idéia é disponibilizar mais um semestre para facilitar a realização do trabalho. A intenção é desencadear todo o processo a partir do quinto semestre ${ }^{12}$ do curso, de maneira que, os licenciandos tenham pelos menos um ano para iniciar os estudos sobre a pesquisa e formular o projeto. Assim, os dois últimos semestres seriam dedicados a coleta, análise dos dados e redação final da monografia.

Um último aspecto merecedor de atenção se refere à produção científica. Na medida em que os trabalhos são finalizados, abre-se a possibilidade para publicação de seus resultados, o que acaba aumentando a produção científica local, além de permitir que os estudantes participem de eventos de divulgação científica ${ }^{13}$, publiquem seus primeiros resumos e artigos, e se motivem a continuar a carreira como pesquisadores em educação.

\section{CONSIDERAÇÕES FINAIS}

A proposta de iniciação à pesquisa promovida no âmbito do curso de Licenciatura em Ciências Biológicas da UESB, demanda ainda algumas modificações, que por um lado poderão corrigir as distorções que pouco a pouco estão aparecendo, e por outro, aperfeiçoar o processo em sua integralidade. Os primeiros alunos que vivenciaram esta experiência acabaram de concluir o curso, e no próximo semestre (2003/II), mais de 25 licenciandos estarão concluindo suas respectivas monografias. Um outro trabalho investigativo será desenvolvido com o objetivo de acompanhar os alunos egressos em sua trajetória profissional.

Os resultados detectados neste trabalho são animadores e projetam a melhoria significativa no processo formativo dos futuros professores, sobretudo no sentido de evitar que a formação dos licenciandos se reduza ao ensino de conteúdos desconexos e distantes da prática de trabalho que eles irão enfrentar nas escolas do ensino básico. Além disso, tem o mérito de apresentar a pesquisa em sua perspectiva educativa e aumentar o interesse dos alunos para as questões ligadas ao exercício do magistério.

Ademais, para o curso de licenciatura o saldo também é considerado positivo porque o processo está induzindo a uma aproximação entre professores que anteriormente trabalhavam de forma isolada; os professores estão direcionando mais atenção para as questões relacionadas ao ensino e aprendizagem, rompendo com a visão arcaica contida na afirmação de que a formação de professores é obra exclusiva dos docentes das matérias pedagógicas (NAGLE, 1987, p. 166). Um aspecto que também contribui para isso é a forma como se organizam os departamentos na UESB. Os departamentos têm autonomia para contratar docentes na área de educação para atuarem em cada um dos cursos de graduação. Por exemplo, o Departamento de Ciências Biológicas possui em seu quadro de docentes, professores formados em Ciências Biológicas com Mestrado e Doutorado na área de Educação/Educação em Ciências. Acreditamos que essa é uma vantagem em

\footnotetext{
12 Atualmente o processo é desencadeado no sexto semestre.

13 Além disso, como indica Lüdke (2001), a participação constante em eventos científicos pode colaborar na formação dos próprios professores.
} 
comparação às instituições em que os professores da prática de ensino são vinculados aos departamentos de educação. Esse tipo de organização acaba colaborando para ampliar a separação entre os docentes da área pedagógica e os docentes das áreas específicas. No caso estudado neste trabalho, não ocorre esse tipo de distanciamento, professores da área específica e pedagógica pertencem a um mesmo departamento e estão juntos diariamente, o que facilita a aproximação e o planejamento de atividades em conjunto.

Os resultados obtidos a partir desta investigação, ainda que preliminares, fortalecem o argumento de que a introdução de episódios de pesquisa, associados aos trabalhos de final de curso, é condição necessária para alterar o perfil de saída dos licenciandos, contribuindo para a formação de profissionais que tenham na pesquisa um instrumento para aprendizagem permanente e constante atualização.

A sensação do pesquisador frente aos acontecimentos observados é que está sendo criada uma cultura de formação docente, em que os professores e alunos atuam de modo a gerar ambiente acadêmico comprometido com a pesquisa e suas aplicações no campo educacional, sobretudo com a finalidade de aproximar o ensino de graduação da problemática existente nas escolas públicas da região.

Entre as sugestões que foram formuladas para o aprimoramento do processo está a realização de reuniões que aglutinem os professores participantes do processo e outros que porventura queiram participar (como orientadores ou pareceristas), para discutir questões pertinentes às pesquisas realizadas. O processo de orientação individual está funcionando a contento, mas é preciso incentivar mais intensamente o sistema de co-orientação, e envolver mais professores no processo, porque é nessas circunstâncias que a integração entre os docentes de áreas diferentes é potencializada.

A sugestão para aumentar a carga horária destinada aos estudos para monografia está sendo estudada com especial atenção. Como já foi dito, a idéia é antecipar o processo em pelo menos um semestre, de modo que, os licenciandos tomem contato com iniciação em pesquisa educacional a partir da segunda metade do curso. Mas um aspecto altamente positivo é que neste curso, os trabalhos de final de curso estão incluídos como atividade curricular, e portanto, não se trata de uma atividade facultativa, optativa, extracurricular ou de complemento curricular. Os licenciandos precisam entregar a monografia como condição para obtenção da respectiva licença. Tal fato é crucial para que as atividades ligadas à iniciação à pesquisa não sejam tomadas por professores e alunos, como atividades de caráter secundário, em relação às disciplinas, estágios e outras atividades previstas para o processo de formação.

Por fim, alguns estudantes e professores mencionaram a questão da realização de bancas de defesa, onde os estudantes poderiam apresentar oralmente seus trabalhos, complementando a avaliação da monografia já realizada pelos pareceristas. Esta proposta também será analisada no futuro próximo.

Embora seja necessário aprofundar os estudos investigativos sobre o processo de formação como um todo, a nosso ver, a proposta em implantação apresenta mérito, na medida que, encoraja os licenciandos para que eles se engajem em projetos de pesquisa e desenvolvam a capacidade de produção própria, fomentando a prática da pesquisa nos cursos de licenciatura. Iniciativas como essa são fundamentais para privilegiar os cursos de licenciatura, evitando a tendência cristalizada na academia, de menosprezo às questões de ensino e de formação para o exercício do magistério. 


\section{REFERÊNCIAS BIBLIOGRÁFICAS:}

ALVES-MAZZOTTI, A. J. (2001). Relevância e aplicabilidade da pesquisa em educação. Cadernos de Pesquisa, n. 113, p. 39-50, julho/2001.

BASTOS, F.; CALDEIRA, A. M. A. (2000). Prática de ensino de ciências e biologia: novas possibilidades. In: ESCOLA DE VERÃO PARA PROFESSORES DE PRÁTICA DE ENSINO DE FÍSICA, QUÍMICA, BIOLOGIA E ÁREAS AFINS, 5, 2000, Bauru. Caderno de Textos. Bauru: Unesp/FC; Programa de Pós-Graduação em Educação para Ciência; Departamento de Educação, 2000. p.56-60.

BOGDAN, R.; BIKLEN, S. (1994). Investigação qualitativa em educação: uma introdução à teoria e aos métodos. Porto: Porto Editora.

DELIZOICOV, D.; ANGOTTI, J. A.; PERNAMBUCO; M. M. (2002). Ensino de ciências: fundamentos e métodos. São Paulo: Cortez.

DEMO, P. (2002). Educar pela pesquisa. 5. ed. Campinas/SP: Autores Associados. (1997). Desafios modernos da educação. 6. ed. Petrópolis: Vozes.

FURIÓ, C.; GIL-PÉREZ, D. (1989). La didáctica de las ciencias en la formación inicial del profesorado: una orientación y un programa teóricamente fundamentados. Enseñanza de la Ciencias, 7 (3), 257-65.

GALIAZZI, M. C.; MORAES, R. (2001). Pesquisar em aula: espaço de transformação na formação do professor de ciências. In: ENCONTRO NACIONAL DE PESQUISA EM EDUCAÇÃO EM CIÊNCIAS, 3., 2001. Atibaia. Atas... Atibaia: Associação Brasileira de Pesquisa em Educação em Ciências, 2001. CD ROM.

GIL-PÉREZ, D.; CARVALHO, A. M. P. (2000). Formação de professores de ciências. 4. ed. São Paulo: Cortez.

LÜDKE, M (org.). (2001). O professor e a pesquisa. Campinas/SP: Papirus.

LÜDKE, M.; ANDRÉ, M. E. D. A. (1986). Pesquisa em educação: abordagens qualitativas. São Paulo: EPU.

MACHADO, O. V. M. (1999). Novas práxis educativas no ensino de ciências. In: CAPPELLETTI, I. F.; LIMA, L. A. N. Formação de educadores: pesquisas e estudos qualitativos. São Paulo: Olho d'água.

MOREIRA, M. A. (1991). O professor/pesquisador como instrumento de melhoria no ensino de ciências. In: MOREIRA, M. A. e AXT, R. (orgs.). Tópicos em ensino de ciência. Porto Alegre: Sagra. 
NAGLE, J. (1987). As unidades universitárias e suas licenciaturas: educadores $X$ pesquisadores. In: Universidade, escola e formação de professores. São Paulo: Brasiliense. p. 161-172.

NÓVOA, A. (1992). Os professores e sua formação. Lisboa: Dom Quixote.

PORLÁN, R. (1987). El maestro como investigador en el aula. Investigar para conecer, conecer para enseñar. Investigación en la Escuela, 1, p. 63-70.

SCHÖN, D. A. (1992). Formar professores como profissionais reflexivos. In: NÓVOA, A. (org.). Os professores e sua formação. Lisboa: Dom Quixote, p.77-92.

SEVERINO, A. J. (2001). A importância do ler e do escrever no ensino superior. In: CASTANHO, S.; CASTANHO, M. E. (orgs.). Temas e textos em metodologia do ensino superior. Campinas: Papirus, p.71-79.

VIANNA, D. M.; CARVALHO, A. M. P. (2001). Do fazer ao ensinar ciência: a importância dos episódios de pesquisa na formação de professores. Investigações em Ensino de Ciências, v. 6., $\quad$ n. $2, \quad$ Agosto, 2001.2 Disponível em: <www.if.ufrgs.br/public/ensino/vol6/n2/v6_n2_a1.htm>. Acesso: 14.mar.2003.

YAGER, R. E.; PENICK, J. E. (1983). Analysis of the current problems with school science in the USA. European Journal of Science Education, v. 5, 463-59.

Data de recebimento: $18 / 12 / 2003$

Data de aprovação: 25/04/2004 